\title{
MODIFICATION OF THE HYDRATION PROCESSES OF ALKALI ACTIVATED BLAST FURNACE SLAG
}

\author{
${ }^{1}$ Michaela TOPINKOVÁ, 'ozef VLČEK, 'Miroslava KLÁROVÁ, ${ }^{1}$ Hana OVČAČíKOVÁ, \\ ${ }^{1}$ Petra MAIEROVÁ, ${ }^{1}$ Veronika BLAHU゚ŠKOVÁ \\ VSB - Technical University of Ostrava, Ostrava, Czech Republic, EU, \\ jozef.vlcek@vsb.cz, michaela.topinkova@vsb.cz, miroslava.klarova@vsb.cz, hana.ovcacikova@vsb.cz, \\ petra.maierova@vsb.cz,veronika.blahuskova@vsb.cz
}

https://doi.org/10.37904/metal.2020.3455

\begin{abstract}
Granulated blast furnace slag exhibits latent hydraulic properties and its binding properties can be evoked by the addition of the alkali activator. Subsequent hydration processes during the setting and hardening processes let to origination of the solid products with the mechanical properties comparable or even better than the product obtained with ordinary Portland cement. The dominant product of the hydration processes is so called $\mathrm{C}-\mathrm{S}-\mathrm{H}$ phase. C-S-H phases are non-crystalline products of hydration with variable composition based on $\mathrm{CaO}, \mathrm{SiO} 2$ and $\mathrm{H}_{2} \mathrm{O}$. C-S-H phases are responsible for good mechanical properties of the hydrated products. The paper deals with the effect of the addition of the synthetically produced C-S-H phases on the hydration processes of granulated blast furnace slag. C-S-H phases were synthesized using the sol-gel method and were added to the granulated slag at the beginning of its hydration with the role of the nuclei of the phases responsible for strength of the final hydrated products. The mechanical properties as well as the development of the porous structure of hydrated products were used for the evaluation of the effect of the nuclei addition on the hydration process. It was proved that the addition of the synthetically prepared C-S-H nuclei has a positive effect on the development of the mechanical properties of alkali activated blast furnace slag, especially during the initial period of hardening.
\end{abstract}

Keywords: Granulated blast furnace slag, alkali activation, C-S-H phase

\section{INTRODUCTION}

Latent hydraulic materials can be used as an alternative to traditional hydraulic binders. These materials are not able to react with water on their own, but they need so called activators for hydration resulting in products of similar properties like hydrating materials. The main requirement on these materials is that all or at least basic parts of $\mathrm{SiO}_{2}$ and $\mathrm{Al}_{2} \mathrm{O}_{3}$ from raw materials should be in non-crystalline (reactive) form. A material may or may not contains a significant amount of $\mathrm{CaO}$. Other accompanying oxides can be also included. Main raw materials for alkali activation seem to be relatively abundant latent hydraulic materials - metallurgical slags. These systems are typical for their high amount of glassy phase. By their blending with alkaline solutions hydraulic systems form, which solidify and harden [1], [2], [3]. A granulated blast furnace slag (GBFS) perfectly fulfils conditions for alkali activation. The slag contains about 40 wt. \% of $\mathrm{SiO}_{2}$ which results in its certain amorphous character after its fast cooling down. A slag is commonly used as a valuable ingredient in cement production. In this product slag refills development of required phases in combination with Portland clinker. Apart from this application, lots of researches focusing on activation of slag on its own, where the activator of hydraulic ability is soluble blend of alkali silicates, most often a water glass. 
In the process of alkali activation, a disconnection of strong bond between aluminous and siliceous tetrahedrons in primary material occurs at first. This is caused by highly alkaline environment, where created ionic remains transform to liquid state. In next step new react products forms, which results in solidification and hardening. When initial material contains expect $\mathrm{SiO}_{2}$ and $\mathrm{Al}_{2} \mathrm{O}_{3}$ also significantly bigger amount of $\mathrm{CaO}$ (e.g. GBFS), C-S-H phases are main reaction products with considerable amount of tied $\mathrm{Al}^{3+}$ and adsorbed alkalines. $\mathrm{N}$ opposite case, when was used system with zero or very small amount of $\mathrm{CaO}$ (e.g. based on metakaolin), mainly amorphous products form similar to natural zeolites [2], [4], [5], [6].

Essential functional parameters of harden binder or composite material are their strength characteristics, especially compressive strength, also alkali environment resistance. These criteria strongly depend on arrangement of hydrated system, which is evaluated as a porosity. Harden cement binder then contain three types of pores [3]. Gel pores, with medium size of several nm. Capillary pores, with size of 1-10 $\mu \mathrm{m}$ and macro pores, with size of $\mathrm{mm}$.

Knowledge of alkali activated materials microstructure is significant. Mechanical strength of binder definitely related to its composition, network of pores plays a significant role for determination of its lifetime. Main degradation mechanisms of alkali activated binders conclude interaction of aggressive agents. When these systems are porous a bit or non-porous, aggressive agents cannot get into material and damage a chemical structure or cause corrosion of input reinforce [4], [7].

An obvious relationship with porosity of matters has a compressive strength - lower porosity means higher strength and vice versa. At the same time the porosity also closely involved with corrosion behaviour of matters.

An evolution of structure of hydrated material depends on nucleation and consequent growth of crystals. Nucleation from homogenous environment indicates formation of aggregates, of which sizes will be nanometric. In this case, formation of these nuclease is connected with creation of new phase interphase. Transport of molecules from original homogenous phase to new stable phase (e.g. from liquid to crystal) is connected with decrease of Gibbs energy of system, whereas process of formation of new phase interphase is connected with increase of Gibbs energy of system. Sum of these two parts has maximal $\Delta G^{*}$ at critical size of nuclei. About real nuclei can be talked only when creates the structure of that size, which is able to grow more at lower total Gibbs energy [3].

A value of energetic barrier $\Delta G^{*}$ can be decreased by a presence of foreign surface in system, which can be mainly purposely introduced particles. In such cases it is a heterogeneous nucleation. Today, it is used in some technologies (e.g. production of glass-ceramics). Nuclease, which are oversized, they grow thanks to supply of matter from neighbourhood. The speed of this growth is given by a sum of the speed of surface process, which step into a structure of new phase and the speed of matters creating a new phase achieves a surface of nuclease. An important role plays also temperature affecting diffusion processes [3].

Researches carried out on field of improvement of properties of harden binders and composites are oriented on so called nano-cements and nano-concretes, for example [8]. More compact microstructure is formed due to addition of very fine grain particles, e.g. nano-silica, nano- $\mathrm{TiO}_{2}$, nano-montmorillonite, etc. This type of process can vary, nano-particles can fulfil an active, as well as a non-active role.

In the case of cements, and pozzolans as well, it can be interesting option an acceleration of reaction in initial stages of hydration by adding of crystallization nuclei. These nuclei will provide conditions for faster nucleation of neoplasms, they also create stronger grows together among them, more idyllic overgrowing of basic skeleton matter of microstructure and following refiling by calcium silicate hydrated gel, also they can be an active reactant in forming mineral ettringite. For example, it can be recommended an option of preparation of crystallization nuclei by fast cooling down of Portland clinker in water from about $1400^{\circ} \mathrm{C}$ to $50-100{ }^{\circ} \mathrm{C}$ with following isothermal staying. During this process, xonolite is created, which forms suitable crystallization nuclei at hydration of cement [4], [9]. 


\section{EXPERIMENT AND DISCUSSION}

This work consists in research of microstructure of harden alkali activated systems based on granulated blast furnace slag which are modified by addition of synthetically prepared nucleating agent, which are nano particles of $\mathrm{C}-\mathrm{S}-\mathrm{H}$ phases (where $\mathrm{C}-\mathrm{CaO}, \mathrm{S}-\mathrm{SiO}_{2}, \mathrm{H}-\mathrm{H}_{2} \mathrm{O}$ ), which were created by sol-gel technique through a solution. These nucleating agents are able to affect kinetics and degree of formation of bonding C$\mathrm{S}-\mathrm{H}$ phase, which arise from hydration in alkali activated system of granulated blast furnace slag and thus a final porosity of product. Phases C-S-H are described very well in the case of hydrated Portland cement, where are responsible for the strength of this product [9]. Phases C-S-H emerge also during hydration of granulated blast furnace slag from the effect of alkali activator, they create a dominant part in given product, another present phase are geopolymer structures [10]. A development of C-S-H phases is gradual in the case of granulated blast furnace slag. Presented work aims at support of their formation and speeding the process.

\subsection{Raw materials}

Raw materials used for observing of effects of nucleating agent on structure of alkali activated matters were granulated blast furnace slag, solution of water glass and C-S-H phases. Solution of water glass was treated on silicate modulus $\mathrm{Ms}=2.0$ by $50 \%$ solution of $\mathrm{NaOH}$. C-S-H phases were prepared in laboratory (from powdered hydrous sodium disilicate, calcium nitrate tetrahydrate and distilled water by the method through a solution, in chosen concentration 0.75 and 5 wt.\% of nucleating agent) and leaved for aging for 7 and 28 days in closed bottle at ambient temperature.

\subsection{Specification of C-S-H colloidal solution}

Above mentioned matters were mutually homogenized in amount guaranteeing required concentrations at ambient temperature for a one hour, when nuclei of C-S-H phases instantly form.

A part of prepared C-S-H colloidal solution was filtered, gradually dried at $30{ }^{\circ} \mathrm{C}$ to the constant weight. On particles made by this way, it was carried out X-Ray diffraction (Bruker D8 Advance), determined chemical composition by X-Ray fluorescence (Rigaku Supermini200) and thermal analyses DTA and TG (STA 504).

X-Ray diffraction proved directly amorphous character of C-S-H particles with the only crystalline phase of $\mathrm{CaCO}_{3}$, how it is supported on Figure 1. A chemical composition of $\mathrm{C}-\mathrm{S}-\mathrm{H}$ particles shows Table 1. By a recalculation of determined weight percentage and molar weights a molar coefficients of an individual parts of colloidal solution were defined: $1.78 \mathrm{CaO} \cdot \mathrm{SiO}_{2} \cdot 4.78 \mathrm{H}_{2} \mathrm{O}$. Introduced composition is close to composition of substance $1.7 \mathrm{CaO} \cdot \mathrm{SiO}_{2} \cdot 4 \mathrm{H}_{2} \mathrm{O}$, which became from cement hydrating phase $\mathrm{C}_{3} \mathrm{~S}$ [11].

Table 1 Chemical composition of used C-S-H nucleating agent

\begin{tabular}{|c|c|c|c|c|c|c|}
\hline Compound & (wt.\%) & Compound & (wt.\%) & Compound & (wt.\%) & L.o.l. (wt.\%) \\
\hline $\mathrm{CaO}$ & 60.11 & $\mathrm{SiO}_{2}$ & 36.18 & $\mathrm{Na}_{2} \mathrm{O}$ & 3.45 & 35 \\
\hline
\end{tabular}

DTA and TA analyses were carried out on STA 504. Speed of heating was $10 \mathrm{~K} \cdot \mathrm{min}^{-1}$ in oxygen atmosphere, amount of air $5 \mathrm{I} \cdot \mathrm{h}^{-1}$. Result of thermal analysis illustrates Figure 2. First endothermic lag between 20 and 180 ${ }^{\circ} \mathrm{C}$ (accompanied by loss of weight $13 \%$ ) corresponds to release of water during heating of structure $\mathrm{C}-\mathrm{S}-\mathrm{H}$ particles. Following linear part of weight loss, which corresponds to release of stronger bonded water from restructured C-S-H. This is followed by second endothermic delay between 500 and $700{ }^{\circ} \mathrm{C}$ (loss of weight 16 $\%$ ). This lag belongs to decomposition of $\mathrm{CaCO}_{3}$. Last endothermic delay follows between 700 and $800{ }^{\circ} \mathrm{C}$ with loss of weight about $4 \%$. Here can be observed stronger change of thermos-physical characteristics, followed by dihydroxylation of $\mathrm{C}-\mathrm{S}-\mathrm{H}$ phase (tobermorite type) and also beginning of formation of pseudowollastonite phase (formation of wollastonitic structure). 


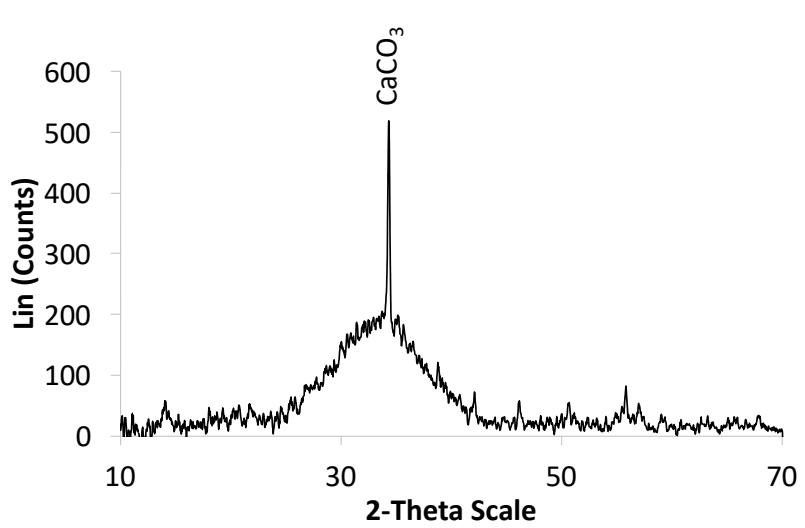

Figure 1 RTG pattern of C-S-H particles

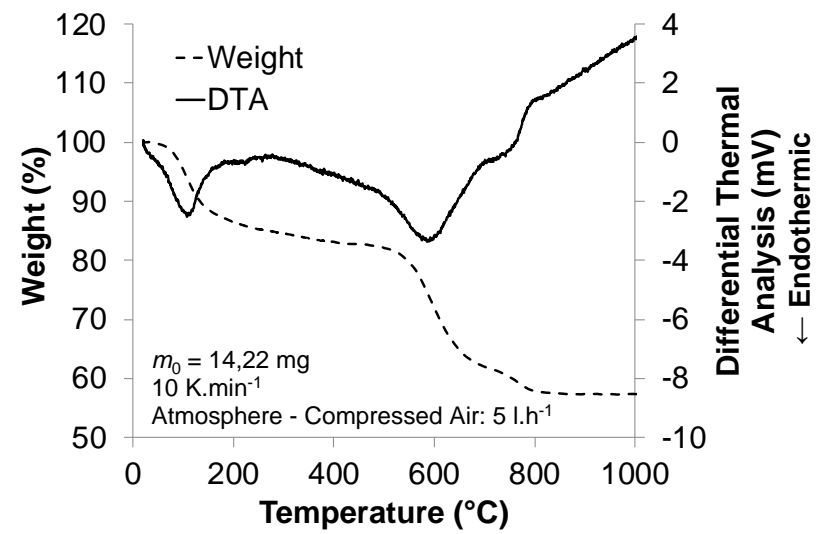

Figure 2 STA record of C-S-H particles

\subsection{Activation of Granulated Blast furnace slag}

Several types of samples were prepared, which were created from above mentioned and described raw materials. These samples differed only in various concentration of nucleating agent. Table 2 presents composition of prepared mixes.

Granulated Blast furnace slag was mixed with nucleating agent properly. In next step an alkali activator was implemented (water glass) in constant amount (due to ensure introducing of $4.5 \mathrm{hm} \% \mathrm{Na}_{2} \mathrm{O}$ ) in the way to be each particle of mix in contact with activator. Finally, distilled water was added up to water coefficient required for optimal consistency of mix. As a referent samples were used that prepared only from pure Granulated Blast furnace slag, where were added water glass and water.

In chosen data 2, 7, 28 and 40 days, samples were taken to examine a compressive strength.

Table 2 Identification of samples and their composition

\begin{tabular}{|c|c|c|c|c|c|c|c|}
\hline Sample & GBFS & \multicolumn{2}{|c|}{${ }^{*}$ C-S-H7 } & \multicolumn{2}{c|}{${ }^{* *}$ C-S-H28 } & Waterglas & Water \\
\hline & $(\mathrm{g})$ & \multicolumn{2}{|c|}{$\left(\mathrm{cm}^{3}\right)$} & \multicolumn{2}{c|}{$\left(\mathrm{cm}^{3}\right)$} & \\
\hline & & $\begin{array}{c}\text { concentracion } \\
0.75\end{array}$ & $\begin{array}{c}\text { concentracion } \\
5\end{array}$ & $\begin{array}{c}\text { concentracion } \\
0.75\end{array}$ & $\begin{array}{c}\text { concentracion } \\
5\end{array}$ & \\
\hline K117 & 150 & 0 & 0 & 0 & 0 & 41.5 & 9 \\
\hline K217 & 150 & 9 & 0 & 0 & 0 & 41.5 & 0 \\
\hline K317 & 150 & 0 & 9 & 0 & 0 & 41.5 & 0 \\
\hline K417 & 150 & 0 & 0 & 9 & 0 & 41.5 & 0 \\
\hline K517 & 150 & 0 & 0 & 0 & 9 & 41.5 & 0 \\
\hline
\end{tabular}

${ }^{*} \mathrm{C}-\mathrm{S}-\mathrm{H} 7$ - synthetically prepared nucleating agent, age of 7 days

${ }^{* *} \mathrm{C}-\mathrm{S}-\mathrm{H} 28$ - synthetically prepared nucleating agent, age of 28 days

\subsection{Determination of Compressive strength (CCS)}

In given term, a three values of strength of parallel samples from each mix were determined. From these measured data the average values were calculated, which are given on Figure 3 and Figure 4.

From that picture there is obvious, that use of all nucleating agents increased a compressive strength after 2 and particularly after 7 days. Achieved values of strength after two days of samples hydration are at level 80 $\mathrm{MPa}$, where referent sample K117 gained only strength of $45 \mathrm{MPa}$. Positive effect shows presence of nuclei 
also on values of long term strength. After 40 days of hydration is strength of samples with 7 days old nuclei comparable, but in the case of 28 days old nuclei the difference is up to $27 \%$.

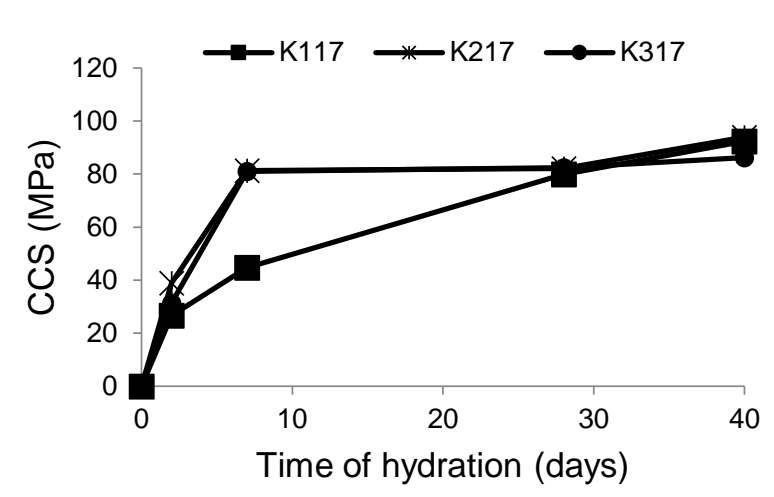

Figure 3 Compressive strength (CCS) of sample $\mathrm{K} 117$ and of samples with addition of nucleating agent C-S-H (7 days old nuclei)

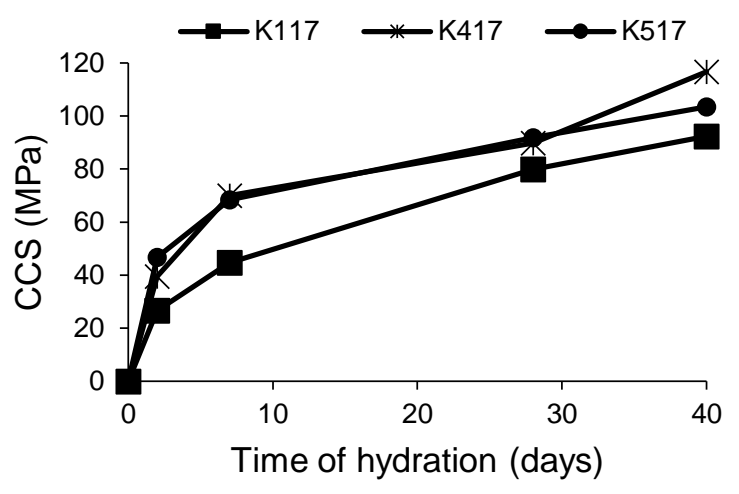

Figure 4 Compressive strength (CCS) of sample $\mathrm{K} 117$ and of samples with addition of nucleating agent C-S-H (28 days old nuclei)

\subsection{Mercury porosimetry}

After 7 days of hydration more pronounced affecting of strength reached. Based on this finding an evaluation of effect of nucleating agent on structural changes of phase composition through mercury porosimetry has been carried out. Bodies in shape of beam $15 \times 5 \times 5 \mathrm{~mm}$ were cut from samples, these were dried for 24 hours at $50{ }^{\circ} \mathrm{C}$, when free water from pores release. Porosity of alkali activated matters were determined on AUTOPORE 9500.

Table 3 Results of porosimetry measurements

\begin{tabular}{|l|c|c|c|c|c|c|}
\hline \multirow{2}{*}{ Sample } & \multicolumn{4}{|c|}{$\begin{array}{c}\text { Pores volume } \\
{\left[\mathrm{cm}^{3} \cdot \mathrm{g}^{-1}\right] \cdot 10^{2}}\end{array}$} & $\begin{array}{c}\text { Average pore } \\
\text { size } \\
{[\mu \mathrm{m}]}\end{array}$ & $\begin{array}{c}\text { Porosity } \\
{[\%]}\end{array}$ \\
\cline { 2 - 5 } & total & $10 \sim 100 \mu \mathrm{m}$ & $1 \sim 100 \mu \mathrm{m}$ & $0.1 \sim 100 \mu \mathrm{m}$ & & \\
\hline $\mathrm{K} 117$ & 8.68 & 1.58 & 3.62 & 7.83 & 0.0894 & 15.93 \\
\hline $\mathrm{K} 217$ & 2.11 & 0.63 & 0.93 & 1.04 & 0.0161 & 3.94 \\
\hline $\mathrm{K} 317$ & 5.68 & 0.66 & 0.97 & 1.26 & 0.0126 & 9.82 \\
\hline $\mathrm{K} 417$ & 5.77 & 0.66 & 1.13 & 1.47 & 0.0129 & 10.89 \\
\hline $\mathrm{K} 517$ & 6.69 & 1.07 & 1.98 & 4.87 & 0.0342 & 12.66 \\
\hline
\end{tabular}

In Table 3, there can be seen, that the most significant differences were recorded at total porosity. In the case of referent sample (K117), which was prepared only from pure GBFS, a total porosity was measured $16 \%$. In the case of other samples with nucleating agent was achieved lower total porosity. When used 7 days old C$\mathrm{S}-\mathrm{H}$ phases as a nucleating agent, a total porosity was achieved even much lower (range of $4-10 \%$ comparing to $16 \%$ for sample K117). It was also evaluated pore size distribution from measured records in form of their volume content for given intervals of pore sizes, namely $10 \sim 100 \mu \mathrm{m}, 1 \sim 100 \mu \mathrm{m}$ and $0.1 \sim 100 \mu \mathrm{m}$. The biggest difference is visible in the case of the smallest pores $(0.1 \sim 100 \mu \mathrm{m})$. When used 7 days old C-S-H phases a difference in amount of the smallest pores made up to $87 \%$ of volume of pores (sample K217) comparing to referent sample K117. A sample with 28 days old nuclei (K417) represents this ration even $81 \%$. 


\section{CONCLUSION}

A content of this work was to verify a possibility of affecting the structure of phase composition of alkali activated granulated blast furnace slag in dependency of nucleating agent addition. The aim was to gain materials with high strength values in an initial phase of hydration.

C-S-H colloidal particles fulfilled a role of nucleating agents in alkali activated slags. As the most sufficient, from the point of view of achieved properties, seems a use of nucleating agent C-S-H phase (with 7 days old nuclei). Materials prepared with this nucleating agent showed the highest increase of 7-day compressive strength. A use of nucleating agent C-S-H phase (with 28 days old nuclei) increased 7-day strength less significant. But in long term development of strength an addition of older nucleating agent manifests themselves more favourably.

Results of Mercury porosimetry brought very good imagination about possibility of evaluation of structure of matters affected by addition of nucleating agent. The most significant difference is in values of total porosity. This result documented assumption, that structure, which is created thanks to nucleating agents, is more and faster filled with hydration products and because of that it is also denser. It corresponds with increase of particularly short term strength.

It can be states, that addition of synthetically prepared C-S-H phases by the method of sol-gel to alkali activated Blast furnace slag has a positive effect on development of higher value of compressive strength at hydrated body and simultaneously a lower porosity can be recorded at these products.

\section{ACKNOWLEDGEMENTS}

This research was supported from ERDF "Institute of Environmental Technology - Excellent Research, no. CZ.02.1.01/0.0/0.0/16_019/0000853.

The authors thank Vlastimil Matějka for XRD data, Jiři Burda for TG/DTA analysis.

\section{REFERENCES}

[1] DAVIDOVITS, Joseph. Geopolymer Chemistry and Applications. Saint-Quentin, 2015. ISBN 9782954453118.

[2] ODLER, Ivan. Special Inorganic Cements. Routledgemot E F \& N Spon. 2002. ISBN-0-419-22790-3.

[3] HLAVÁČ, Jan. Základy technologie silikátů. SNTL. Praha. 1981.

[4] PROVIS, John L., VAN DEVENTER, Jannie S. J. Alkali Activated Materials. Springer, London, 2014. ISBN 97894-007-7671-5.

[5] XU, Huan. Van DEVENTER, Jannie.S.J. The Geopolymerization of alumino-silicate minerale. Int. J. Miner. Process., 2000. 59(3). 247-266.

[6] BRANDŠTETR, Jiří. Struskoalkalické betony. Stavivo. 1984. 3. 110-114.

[7] LLOYD, R. R. Department of Chemical and Biomolecular Engineering. PhD Thesis. University of Melbourne. Australia. 2008.

[8] OZYILDIRIN, Celik et all. Exploration investigation of nanomaterials to improve strenght and permeability of concretes. Trans. Res. Record. 2010. 2. 1-8.

[9] URDOWSKI, Wiesłav. Chemia cementu. Warszava. 1991. Wydawnictwo naukove PWN.

[10] VLČEK, Jozef, DRONGOVÁ, Lucie, TOPINKOVÁ, Michaela, MATĚJKA, Vlastimil, KUKUTSCHOVÁ, Jana, VAVRO, Martin, TOMKOVÁ, Václava. Identification of phase composition of binders from alkali-activated mixtures of granulated blast furnace slag and fly ash. Ceramics-Silikáty. 2014, 58(1), 79-88. ISSN 0862-5468.

[11] TAYLOR. Harry Francis West. Cement chemistry. London. Thomas Telford Publishing. 1997. ISBN 0-7277-25920 . 